\title{
COMPARISON OF BLOOD CULTURE WITH SLIDE AND TUBE WIDAL AGGLUTINATION TESTS IN THE DIAGNOSIS OF TYPHOID FEVER.
}

Krati R. Varshney ${ }^{1}$, Shipra Singhal2 ${ }^{2}$ Shadma Yaqoob³, Priyanka Shukla ${ }^{4}$, YI Singh ${ }^{5}$.

1. Junior Resident, Department of Microbiology, Era's Lucknow Medical college \& hospital.

2. Junior Resident, Department of Microbiology, Era's Lucknow Medical college \& hospital.

3. Assistant Professor, Department of Microbiology, Era's Lucknow Medical college \& hospital.

4. Assistant Professor, Department of Microbiology, Era's Lucknow Medical college \& hospital.

5. Professor \& H.O.D, Department of Microbiology, Era's Lucknow Medical college \& hospital.

\section{CORRESPONDING AUTHOR:}

Krati R. Varshney,

A-17, New Girls Hostel,

Era's Lucknow Medical

College \& Hospital Lucknow.

E-mail: krativarshney2001@yahoo.co.in

\section{HOW TO CITE THIS ARTICLE:}

Krati R. Varshney, Shipra Singhal, Shadma Yaqoob, Priyanka Shukla, Dryi Singh. "Comparison of Blood Culture with Slide and Tube widal Agglutination Tests in the Diagnosis of Typhoid Fever". Journal of Evolution of Medical and Dental Sciences 2013; Vol2, Issue 25, June 24; Page: 4581-4586.

\begin{abstract}
BACKGROUND: Typhoid fever, caused by Salmonella Typhi, is endemic in the Indian sub-continent including Bangladesh, South-east and Far-east Asia, Africa and South Central America. The disease can occur in all age group with highest incidence among children. A simple, reliable, rapid and early diagnostic test has been a long felt need of the clinicians. Blood culture is regarded as the gold standard for diagnosis. However, this requires laboratory equipment and technical training that are beyond the means of most primary health care facilities in the developing countries. To fulfill the purpose the present study was carried out in the Department of Microbiology, Era's Lucknow Medical College and Hospital for the period from Oct 2012 to Mar 2013. MATERIALS AND METHODS: 300 blood samples, collected aseptically from patients clinically diagnosed of Typhoid fever, were evaluated by blood culture, Tube and Slide Widal test

RESULTS: This study included 300 cases having clinical suspicion of typhoid fever. Subjects were investigated by blood culture, Tube \& Slide Widal agglutination tests. Among them, 42(14\%) were subsequently confirmed by blood culture for S. Typhi, 123(41\%) and 150(50\%) cases were positive as having significant titre of Slide and Tube Widal agglutination tests respectively. Thus, in comparison to the gold standard test i:e blood culture, Tube and Slide Widal test were better and consumed less time. Comparing Slide and Tube Widal test, Tube is better. CONCLUSION: Tube\& Slide Widal agglutination test is found to be better and could be applied as a good alternate in resource poor nation. Further, it is simple to perform, reliable when compared to blood culture test, and rapid, with results being available in $18 \mathrm{hrs}$ when compared to 48 hours for blood culture.
\end{abstract}

KEY WORDS: Blood culture, Salmonella Typhi, Widal 
INTRODUCTION: Typhoid fever is a severe multisystemic illness characterized by the classic prolonged fever, sustained bacteremia without endothelial or endocardial involvement and bacterial invasion of and multiplication within the mononuclear phagocytic cells of the liver, spleen, lymph nodes and Peyer's patches ${ }^{1}$. Typhoid fever is potentially fatal if untreated. It is caused by Salmonella typhi a Gram negative bacilli2. Typhoid fever is a global health problem. Its real impact is difficult to estimate because the clinical picture is confused with other febrile infections. Incidence of typhoid fever has been estimated as approximately 22 million cases with at least 200,000 deaths occurring worldwide annually3.

Isolation of Salmonella from blood, urine or stool is the most reliable means of confirming an infection. However, this requires laboratory equipment and technical training that are beyond the means of most primary health care facilities in the developing world 4 . In addition, easy availability and widespread use of antibiotics in the community makes it frequently difficult to isolate the organism from blood culture may be difficult, which is invasive and difficult to carry out. ${ }^{5}$ Blood culture is regarded as the gold standard for diagnosis and carry $70-75 \%$ diagnostic yield in the first week of illness. ${ }^{6}$

MATERIALS AND METHODS: This cross sectional study included 300 cases having clinical suspicion of typhoid fever. This study was conducted in Department of Microbiology, Era's Lucknow Medical College \& Hospital, Uttar Pradesh, India during October 2012- March 2013. The blood samples were collected for blood culture and Widal test .The blood culture was done by using brain heart infusion (BHI) broth and it was incubated. Subsequent sub-cultures were made on Mac Conkey's agar and blood agar media after 24, 48 and 96 hours and the final sub-culture was made on the seventh day. The growth of S. Typhi was identified by the standard biochemical tests and it was confirmed by agglutination with the Salmonella polyvalent ' 0 ', 09 and the H: $\mathrm{d}$ antisera. The Widal test was done by using the standard procedure ${ }^{7}$. The Widal test was done by the Slide and Tube agglutination method. It was considered as positive when a titre of equal to or more than 1:80 was observed.

\section{INCLUSION CRITERIA}

i) Fever for $\geq 7$ days, with no obvious focus of infection,

ii) Abdominal discomfort- constipation or loose motions,

iii) Coated tongue, toxic look,

iv) Hepatomegaly, splenomegaly,

v) Relative bradycardia rose spot etc.

\section{EXCLUSION CRITERIA}

i) Persons who were immunized with typhoid vaccines.

ii) Patient suffering from fever other than typhoid.

iii) Patients on antibiotics 


\section{ORIGINAL ARTICLE}

\section{RESULTS}

Table 1: Positive cases by blood culture

\begin{tabular}{|l|l|}
\hline Age in years & Blood culture Positive \\
\hline $1-5=102$ & $15(14.70)$ \\
\hline $6-10=81$ & $12(14.81)$ \\
\hline $11-15=72$ & $09(12.50)$ \\
\hline$>15=45$ & $06(13.33)$ \\
\hline Total $=300$ & $42(14.00)$ \\
\hline
\end{tabular}

Among 300, 42(14\%) were subsequently confirmed on the basis of positive blood culture for S. Typhi

Table 2: Positive cases by Slide Widal agglutination test (SWAT)

\begin{tabular}{|l|l|}
\hline Age in years & SWAT Positive \\
\hline $1-5=102$ & $30(32.35)$ \\
\hline $6-10=81$ & $18(22.22)$ \\
\hline $11-15=72$ & $36(50)$ \\
\hline$>15=45$ & $39(86.66)$ \\
\hline Total $=300$ & $123(41)$ \\
\hline
\end{tabular}

$123(41 \%)$ cases were positive as having significant titre of Slide Widal agglutination test in first sample.

Table 3: Positive cases by Tube Widal agglutination test (TWAT)

\begin{tabular}{|l|l|}
\hline Age in years & TWAT Positive \\
\hline $1-5=102$ & $33(32.35)$ \\
\hline $6-10=81$ & $21(25.92)$ \\
\hline $11-15=72$ & $48(66.66)$ \\
\hline$>15=45$ & $48(66.66)$ \\
\hline Total $=300$ & $150(50)$ \\
\hline
\end{tabular}


$150(50 \%)$ cases were having significant titre of Tube Widal agglutination test. 150 cases neither had blood culture positive result nor significant titre on Widal test, but still were included due to clinically in favour of typhoid fever.

Table 4: Comparison of Blood culture, Slide Widal Agglutination tests (SWAT) and Tube Widal Agglutination tests (TWAT) of first sample among clinically suspected typhoid cases.

\begin{tabular}{|l|l|l|}
\hline \multicolumn{1}{|c|}{ Test } & Positive & Negative \\
\hline & & \\
\hline Blood culture $(n=300)$ & $42(14.00)$ & $258(86.00)$ \\
\hline SWAT $(n=300)$ & $123(41.00)$ & $177(59.00)$ \\
\hline TWAT $(n=300)$ & $150(50.00)$ & $150(50.00)$ \\
\hline
\end{tabular}

Figures in parenthesis indicate percentage.

Thus, in comparison to the gold standard test i:e blood culture, Tube and Slide Widal test were better and were less time consuming. Comparing Slide and Tube Widal agglutination test tube accounted to be better.

DISCUSSION: Isolation of the causative agent by culture has remained the gold standard for diagnosis of enteric fever. Blood culture has got its limited diagnostic utility due to low sensitivity. Although the Widal test has been used for more than a century in many developing countries but it is non-specific, poorly standardized, often confusing and difficult to interpret ${ }^{8}$. Moreover, sharing of $\mathrm{O}$ and $\mathrm{H}$ antigens by other Salmonella serotypes and other members of Enterobacteriaceae makes the role of Widal test even more controversial in diagnosing typhoid fever 9 .

Most of the children presented in the second week of their illness and we used a cut-off titer of 1:80. The use of a higher cut-off titre would have further reduced the sensitivity of the test. Although this has been questioned, ${ }^{10}$ antibiotic therapy has been shown to alter the antibody response to $S$. Typhi infection, 11 and given that a large number of the patients had previously received antibiotics, this factor may have altered the antibody titers against 0 antigens. The Tube Widal Agglutination was significantly more sensitive than the Slide Widal Agglutination test, although the sensitivity lowers than those reported from Malaysia and The Philippines. ${ }^{12-14}$ Our findings of sensitivity were also lower than values $90 \%$ reported recently by Karamat and others 15 from northern Pakistan.

These differences may be due to several factors including the genomic diversity among S. Typhi isolates in the region 16 and differences in antigenic epitopes. Other factors responsible for reported differences in areas of high endemicity are various stages of the illness and the rate of increase of IgG antibodies to the outer membrane proteins (OMPs), which may interfere with identification of concomitant IgM antibodies. Most of our patients presented in the second week of their illness, whereas information on duration of illness is lacking in other studies.12,13,16 The relative low sensitivity of the blood culture in diagnosing typhoid fever is understandable in the wake of widespread antibiotic use ${ }^{17}$ and the difficulties of obtaining large enough blood volumes 
for cultures. Although bone marrow cultures significantly increase the yield from cultures, ${ }^{18-19}$ the comparative study with bone marrow culture is not done in our study. It must be emphasized that although cultures are associated with a lag period of at least $48 \mathrm{hr}$ for preliminary confirmation of infection, with the recent emergence of drug resistance among S. Typhi, they remain an essential investigation. In many circumstances, especially among partially treated cases presenting to health facilities, combining cultures with a serological test may reduce the diagnostic difficulty in typhoid fever. Our data indicate that combining the blood cultures with a Widal Slide \&Tube agglutination tests will significantly improve the diagnostic yield.

CONCLUSIONS: After analyzing the findings of the present study it was concluded that although blood culture is gold standard for diagnosis of typhoid fever, the rising titre of Widal test is also helpful for diagnosis of typhoid fever. Our data indicate that combining the blood cultures with a Widal Slide \&Tube agglutination tests will significantly improve the diagnostic yield. Tube \& Slide widal agglutination test is found to better less time consuming and could be applied as a good alternate in resource poor nation. Further, it is simple to perform, reliable when compared to blood culture test, and rapid, with results being available in $18 \mathrm{hrs}$ when compared to 48 hours for blood culture.

There is an urgent need for the rational design and evaluation of effective and appropriate diagnostics for typhoid fever.

ACKNOWLEDGEMENT: Authors are thankful to all the clinical departments of Era's Lucknow Medical College for providing institutional support to carry out this study.

\section{REFERENCES:}

1. Brusch JL, Garvey T, Corales R, Schmitt SK. 2006. eMedicine from WebMd Typhoid Fever available at http//www.emedicine.com.MED/topic2331.html.

2. Kidgell C, Reichard U, Wain J, Linz B, Torpdahl M, Dougan G et al. Salmonella Typhi, the causative agent of typhoid fever, is approximately 50,000 years old. Infection, Genetics and Evolution 2002; 2: 39-45.

3. Crump JA, Stephen P, Luby ED, Mintz. The global burden of typhoid fever. Bull World Health Organ 2004; 82:1-24.

4. Olsen SJ, Pruckler J, Bibb W, Thi My Thanh N, MyTrinh T et al. Evaluation of Rapid Diagnostic Tests for Typhoid fever. J Clin Microbial 2004; 42:1885-9.

5. Begum Z, Hossain Md A, Shamsuzzaman AKM, Ahsan Md M, Musa AKM, Mahmud Md C et al. Evalutaion of Typhidot (IgM) for Early Diagnosis of Typhoid fever. Bangladesh J Med Microbiol 2009; 3:10-3.

6. Krishna S, Desai S, Anjana VK, Paranthaaman RG. Typhidot (IgM) as a reliable and rapid diagnostic test for typhoid fever. Ann Trop Med Pub Health 2011; 4:42-4.

7. Collee JG, Diguid JP, Fraser A G. Mackie and McCartney Practical Medical Microbiology. 14th Edition Churchill Livingstone, Edinburgh, 1996. Chapter 9, Some serological techniques for microbial and Viral infections; $p$ 179-82

8. Schroeder SA. Interpretation of serologic tests for typhoid fever.Journal of the American Medical Association 1968; 206:839-40. 
9. Parry CM, Hien TT, Dougan G, White NJ, Farrar JJ, Parry CM et al. Typhoid fever. New England Journal of Medicine 2002; 347:1770-82

10. Robertson RP, Abdel Wahab MF, 1970. Influence of chloramphenicol and ampicillin on antibody response in typhoid and paratyphoid fever. Ann Intern Med 72: 219-21.

11. Shukla S, Patel B, Chitnis DS, 1997. 100 years of Widal test and its reappraisal in an endemic area. Indian J Med Res 105:53-7.

12. Choo KE, Oppenheimer SJ, Ismail AB, Ong KH, 1994. Rapid serodiagnosis of typhoid fever by dot enzyme immunoassay in an endemic area. Clin Infect Dis 19: 172-6.

13. Jackson AA, Ismail A, Ibrahim TAT, Kader ZSA, Nawi NM, 1995. Retrospective review of dot enzyme immunoassay testfor typhoid fever in an endemic area. Southeast J Trop Med Public Health 26: 625-30.

14. Choo KE, Davis TM, Ismail A, Tuan Ibrahim TA, Ghazali WN, 1999. Rapid and reliable serological diagnosis of enteric fever: comparative sensitivity and specificity of Typhidot and Typhidot-M tests in febrile Malaysian children. Acta Trop 72:175-83.

15. Karamat KA, Ahmed JU, Abbasi SA, 1998. Detection of serum IgM against Salmonella typhi: a rapid diagnostic technique. J Coll Physicians Surgeons Pak 8: 170-3.

16. Pang T, Altwegg M, Martinetti G, Koh CL, Puthucheary S, 1992. Genetic variation among Malaysian isolates of Salmonella typhi as detected by ribosomal RNA gene restriction patterns. Microbiol Immunol 36: 539-43.

17. Sturm AW, van der Pol R, Smits AJ, van Hellemondt FM, Mouton SW, Jamil B etal, 1997. Over the- counter availability of antimicrobial agents, self-medication and patterns of resistance in Karachi, Pakistan. J Antimicrob Chemother 39: 543-7.

18. Gilman RH, Terminel M, Levine MM, Hernandez-Menodoze P,Hornick RB, 1975. Relative efficacy of blood, urine, rectal swab, bone-marrow and rose spot cultures for recovery of Salmonella typhi in typhoid fever. Lancet 1: 1211-3.

19. Bhutta ZA, 1991. Bone marrow examination in prolonged fever (letter). J Pediatr 119: 840 